\title{
Investigation of Deep Levels in GaInNas
}

F. Abulfotuh, A. Balcioglu, D. Friedman, J. Geisz, and S. Kurtz

National Renewable Energy Laboratory

Presented at the National Center for Photovoltaics Program Review Meeting

Denver, Colorado

September 8-11, 1998

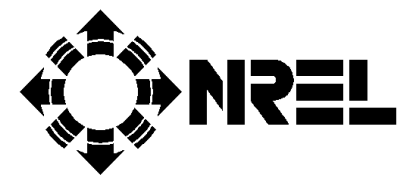

National Renewable Energy Laboratory 1617 Cole Boulevard

Golden, Colorado 80401-3393

A national laboratory of the U.S. Department of Energy Managed by Midwest Research Institute for the U.S. Department of Energy under contract No. DE-AC36-83CH10093

Work performed under task number PV903401

November 1998 


\section{NOTICE}

This report was prepared as an account of work sponsored by an agency of the United States government. Neither the United States government nor any agency thereof, nor any of their employees, makes any warranty, express or implied, or assumes any legal liability or responsibility for the accuracy, completeness, or usefulness of any information, apparatus, product, or process disclosed, or represents that its use would not infringe privately owned rights. Reference herein to any specific commercial product, process, or service by trade name, trademark, manufacturer, or otherwise does not necessarily constitute or imply its endorsement, recommendation, or favoring by the United States government or any agency thereof. The views and opinions of authors expressed herein do not necessarily state or reflect those of the United States government or any agency thereof.

Available to DOE and DOE contractors from:

Office of Scientific and Technical Information (OSTI)

P.O. Box 62

Oak Ridge, TN 37831

Prices available by calling 423-576-8401

Available to the public from:

National Technical Information Service (NTIS)

U.S. Department of Commerce

5285 Port Royal Road

Springfield, VA 22161

703-605-6000 or 800-553-6847

or

DOE Information Bridge

http://www.doe.gov/bridge/home.html 


\title{
Investigation of Deep Levels in GaInNAs
}

\author{
F. Abulfotuh, A. Balcioglu, D. Friedman, J. Geisz, and S. Kurtz \\ National Renewable Energy Laboratory (NREL) \\ Golden, Colorado 80401
}

\begin{abstract}
This paper presents and discusses the first Deep-Level transient spectroscopy (DLTS) data obtained from measurements carried out on both Schottky barriers and homojunction devices of GaInNAs. The effect of $\mathrm{N}$ and In doping on the electrical properties of the GaNInAs devices, which results in structural defects and interface states, has been investigated. Moreover, the location and densities of deep levels related to the presence of $\mathrm{N}, \mathrm{In}$, and $\mathrm{N}+\mathrm{In}$ are identified and correlated with the device performance. The data confirmed that the presence of $\mathrm{N}$ alone creates a high density of shallow hole traps related to the $\mathrm{N}$ atom and structural defects in the device. Doping by In, if present alone, also creates low-density deep traps (related to the In atom and structural defects) and extremely deep interface states. On the other hand, the copresence of In and $\mathrm{N}$ eliminates both the interface states and levels related to structural defects. However, the device still has a high density of the shallow and deep traps that are responsible for the photocurrent loss in the GaNInAs device, together with the possible short diffusion length.
\end{abstract}

\section{INTRODUCTION}

Geisz (1) has shown that GaInNAs can be grown lattice-matched to GaAs with a bandgap of $1.0 \mathrm{eV}$. Initial performance data of prototypes of the GaInNAs solar-cell lattice-matched to GaAs have confirmed its potential for ultrahigh-efficiency three- or four-junction devices. To obtain cells that are more efficient than existing devices, sufficient photocurrent from the $1.0 \mathrm{eV}$ junction must be produced to match the photocurrents of the GaNInAs and GaAs junctions. However, a very low photocurrent and limited quantum efficiency were observed. Initially, this was attributed to short diffusion lengths (2).

The electrical performance of the semiconductor devices is limited by the defects and impurity centers that are present in the bulk, surface, and interface regions. Therefore, possible trap levels near the depletion region of the device can also be a primary potential contributor to the loss in photocurrent. Deep-level transient spectroscopy (DLTS) is one of the most useful techniques for characterizing the deep level in semiconductor devices. This paper presents and discusses the first DLTS data obtained from measurements carried out on both Schottky barriers and heterojunction devices of GaInNAs. 


\section{EXPRIMENTAL METHODS}

\section{Growth of GaNInAs}

GaInNAs was grown by atmospheric and low-pressure metal-organic vaporphase epitaxy using trimethylgallium (TMG), trimethylindium (TMI), arsine $\left(\mathrm{AsH}_{3}\right)$, and 1,1-demethylhydrazine (DMHy). Growth temperatures ranged from $550{ }^{\circ} \mathrm{C}$ to $650{ }^{\circ} \mathrm{C}$. GaNAs, GaInAs, and GaInNAs Schottky barriers were prepared by using Au back and sputtered $\mathrm{Au} / \mathrm{Pd}$ alloy as front contacts.

\section{DLTS Measurements}

DLTS measurements were carried out on these Schottky barriers, in addition to p-n junctions of the GaNInAs devices. Schematics of the structure of Schottky and mono-junction devices are shown by Figures $1 \mathrm{a}$ and $1 \mathrm{~b}$. The configuration of the DLTS

\begin{tabular}{|l|}
\hline $\begin{array}{l}\text { Au grid } \\
\text { p-GaAs }\end{array}$ \\
\hline p-GaInP \\
\hline p-GaInNAs \\
\hline n-GaInNAs \\
\hline n- GaAs buffer \\
\hline n- GaAs substrate \\
\hline Au/Sn back contact \\
\hline p/n homojunction \\
\hline
\end{tabular}

(PA277)

\begin{tabular}{|l|}
\hline Pd grid \\
\hline p-GaInNAs \\
\hline p-GaAs substrate \\
\hline Au back contact \\
\hline
\end{tabular}

Schottky diode

(b)

Figure 1 Schematic diagram of the structure of GaInNAs Schottky (b) and homojunction (a) devices.

system is depicted by the schematic diagram of Figure 2. The system consists of a sensitive capacitance measurement apparatus with adequate transient response, a pulse generator to provide rapid changes in the diode bias, a correlator, a variable-temperature crystal, and a data-acquisition computer. The DLTS measurement is based on the ratewindow concept, where the measuring apparatus only responds when the transient is within this window (3). If the emission rate of an existing trap changes with the sample temperature, the instrument will show a response peak at the temperature at which the emission rate is within the window. The emission rate is given by 


$$
\mathrm{e}=[(\sigma \vee \mathrm{N}) / \mathrm{g}] \exp [-\Delta \mathrm{E} / \mathrm{kT}]
$$

where $\sigma$ is carrier capture cross-section; $v$ is mean thermal velocity of carriers in the band; $\mathrm{g}$ is the degeneracy of the trap level; and $\Delta \mathrm{E}$ is the energy between the trap level and the carrier.

Deep Level Spectrometer

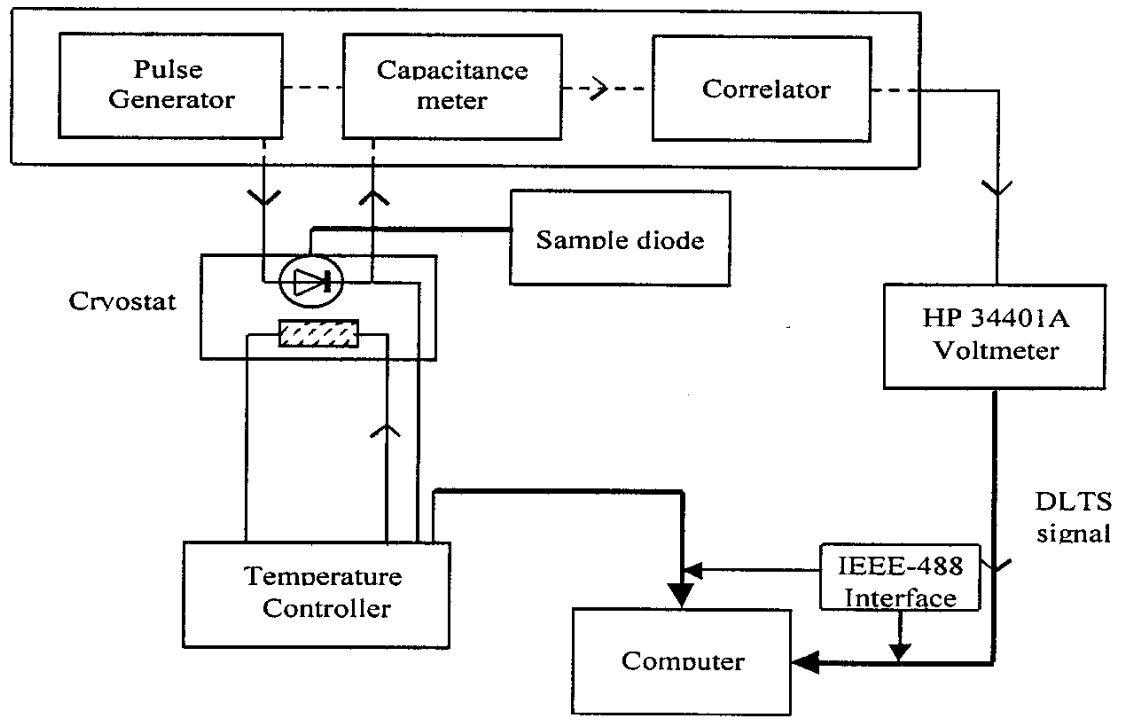

Figure 2 Schematic diagram of the DLTS apparatus.

To determine any possible correlation between the composition of the GaNInAs films and the location of the detected traps and their density, DLTS measurements were carried out on Schottky devices made of GaNAs, GaInAs, and GaNInAs films. In this way, traps related to each of the two dopants were identified. The results of these measurements are illustrated, in the form of DLTS spectra and the associated Arrhenius dependencies, in Figs 3, 4, and 5. Figure 3 shows that two hole traps, HN1 and HN2, are detected in nitrogen-doped p-GaAs films. HN1 is located at $0.13 \mathrm{eV}$. The energy level of HN2 ranges between 0.16 and $0.22 \mathrm{eV}$. The exact location of $\mathrm{NH} 2$ changes with the concentration of $\mathrm{N}$. It is also possible that the density and energy level of HN2 is affected by the presence of $\mathrm{C}$ impurities, which could form $\mathrm{C}-\mathrm{N}$ complex states. In some of the GaNAs devices, an additional hole trap was detected at $0.47 \mathrm{eV}$. The density of this trap $\left(1.4 \times 10^{15} \mathrm{~cm}^{-3}\right)$ is comparable to that of the trap HN2 and is 


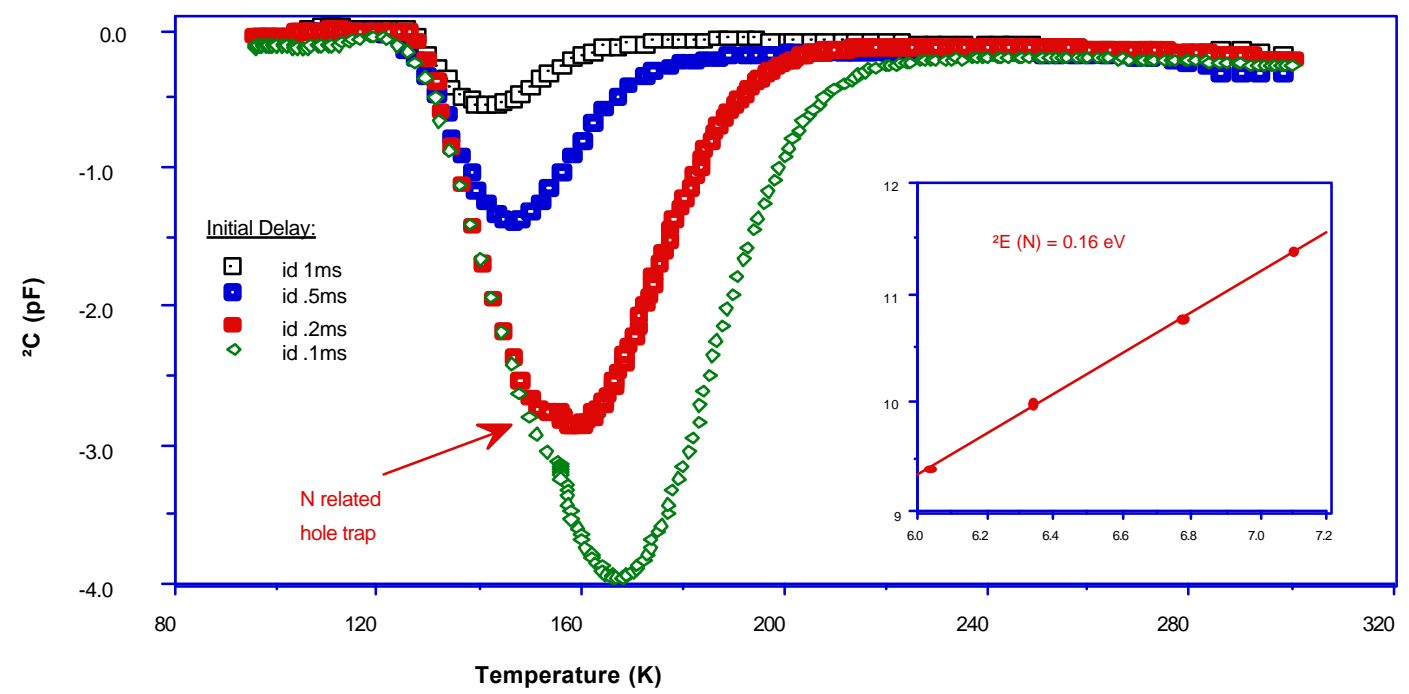

Figure 3 DLTS spectra and Arrhenius plot of GaInAs Schottky diode.

attributed to structural defects in the film. On the other hand, Figure 4 shows that Indoped p-GaAs films are dominated by two levels. The first is a deep hole trap (HIn) at $0.36 \mathrm{eV}$. The second is an extremely deep level at energy levels ranging between 0.91 and $0.94 \mathrm{eV}$ (IIn). The observed change in the intensity of the IIn peak with bias voltage suggested that this level is due to deep interface states. The density of states of the IIn level ranges from $10^{12}$ to $10^{13} \mathrm{~cm}^{-3}$ which is very low compared to the doping density and carrier concentration. We also found that the energy level of IIn shifts to lower energy as the In concentration increases. The hole trap at $0.47 \mathrm{eV}$ due to structural defects is also detected in the GaInAs devices. Two additional traps were observed at the 0.53 and $0.62 \mathrm{eV}$ energy levels. The $0.53 \mathrm{eV}$ trap, which is also observed in the GaNAs devices with high $\mathrm{N}$ concentration (> 5\%), is attributed to structural defects (5). The density of this trap level is two orders of magnitude higher in the GaNAs than in the GaInAs devices. The $0.62 \mathrm{eV}$ hole trap was observed only in the GaInAs devices and is attributed to $\mathrm{Fe}$ impurities (4). Composition analysis carried out using secondary-ion mass spectroscopy confirmed the presence of $\mathrm{Fe}$ impurities. As demonstrated by Figure 5, the presence of HN1, HN2, and HIn is confirmed in Schottky diodes made of GaNInAs. But only HN2 and HIn were detected in p-n mono-junction GaNInAs devices ( Figure 6). It is worth noting that the hole trap 


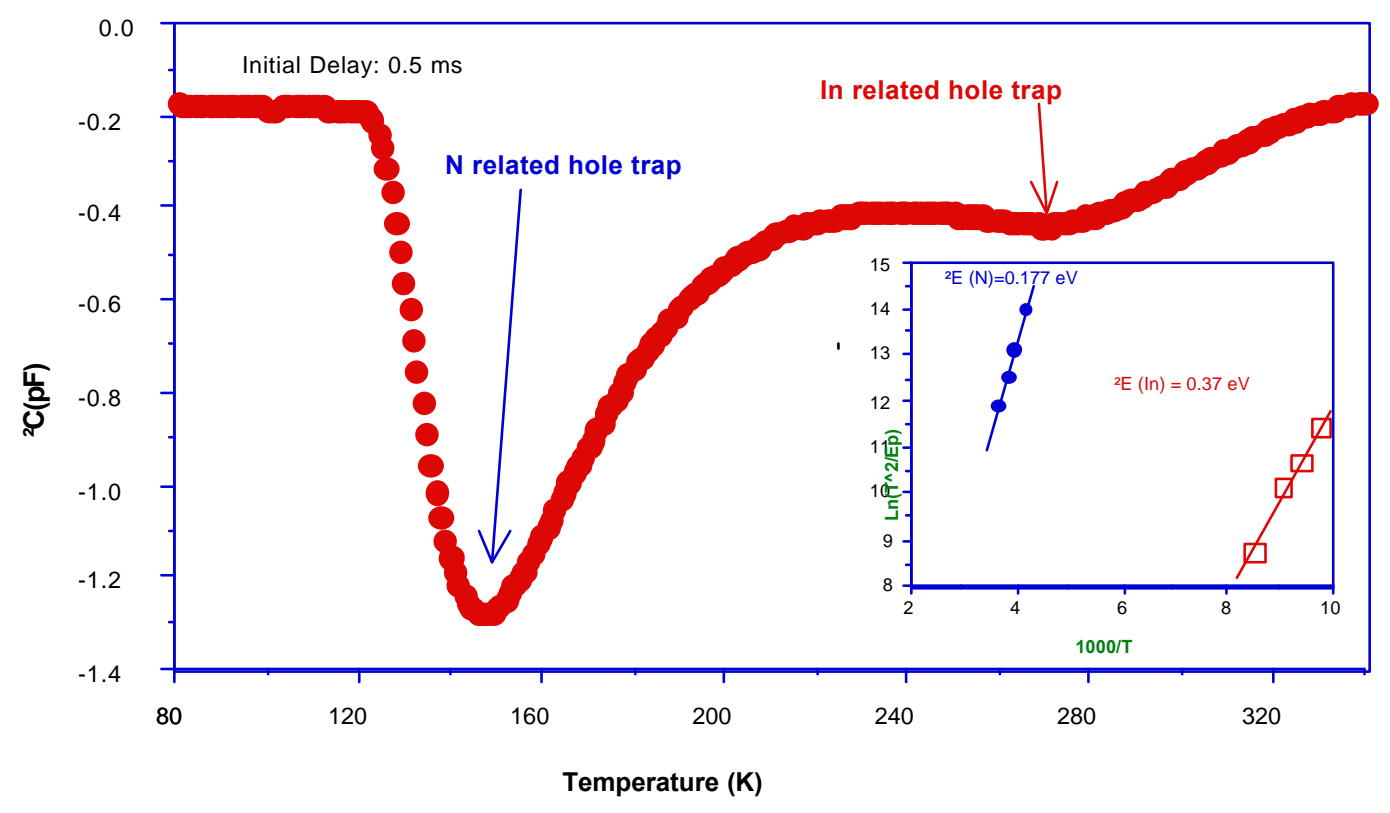

Figure 4 DLTS spectra and Arrhenius plot of GaInAs Schottky diode.

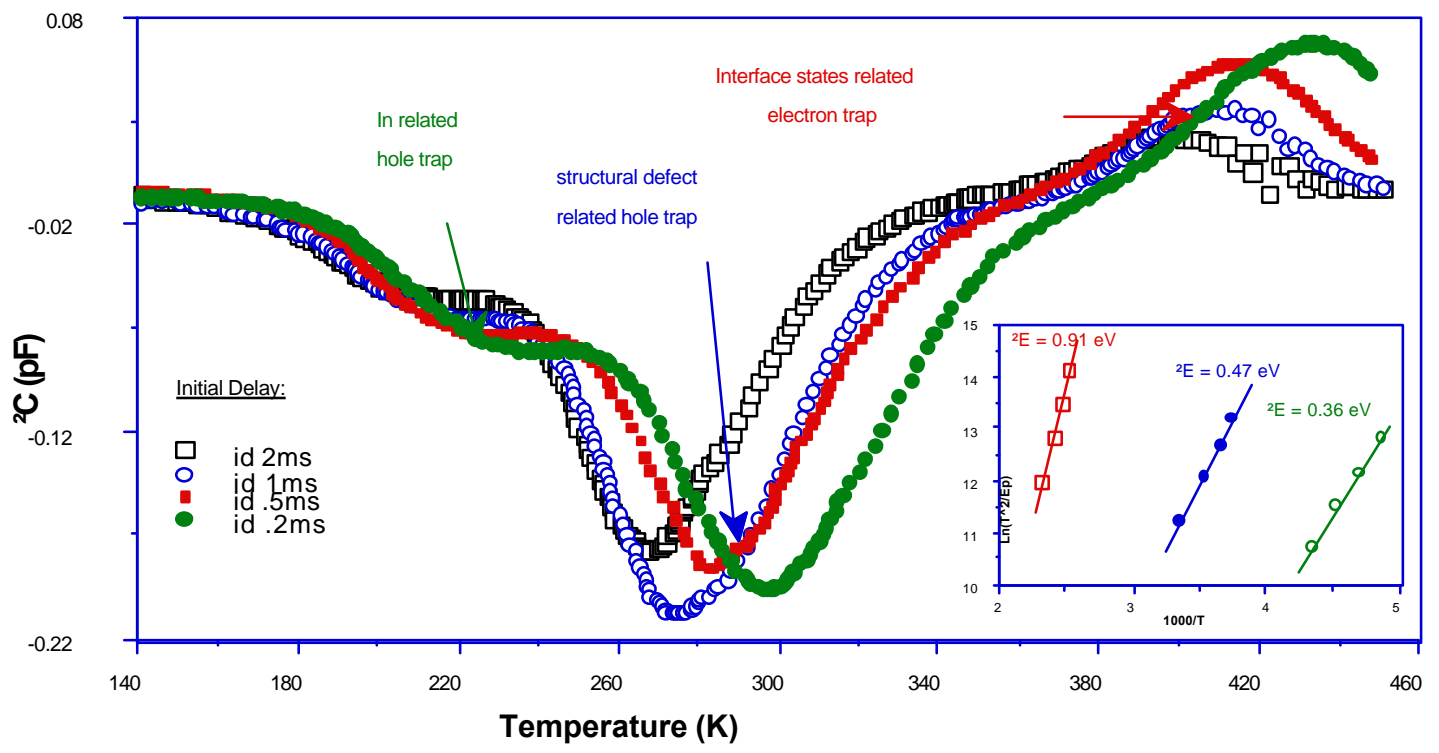

Figure 5 DLTS spectra and Arrhenius of GaInNAs schottky diode. 


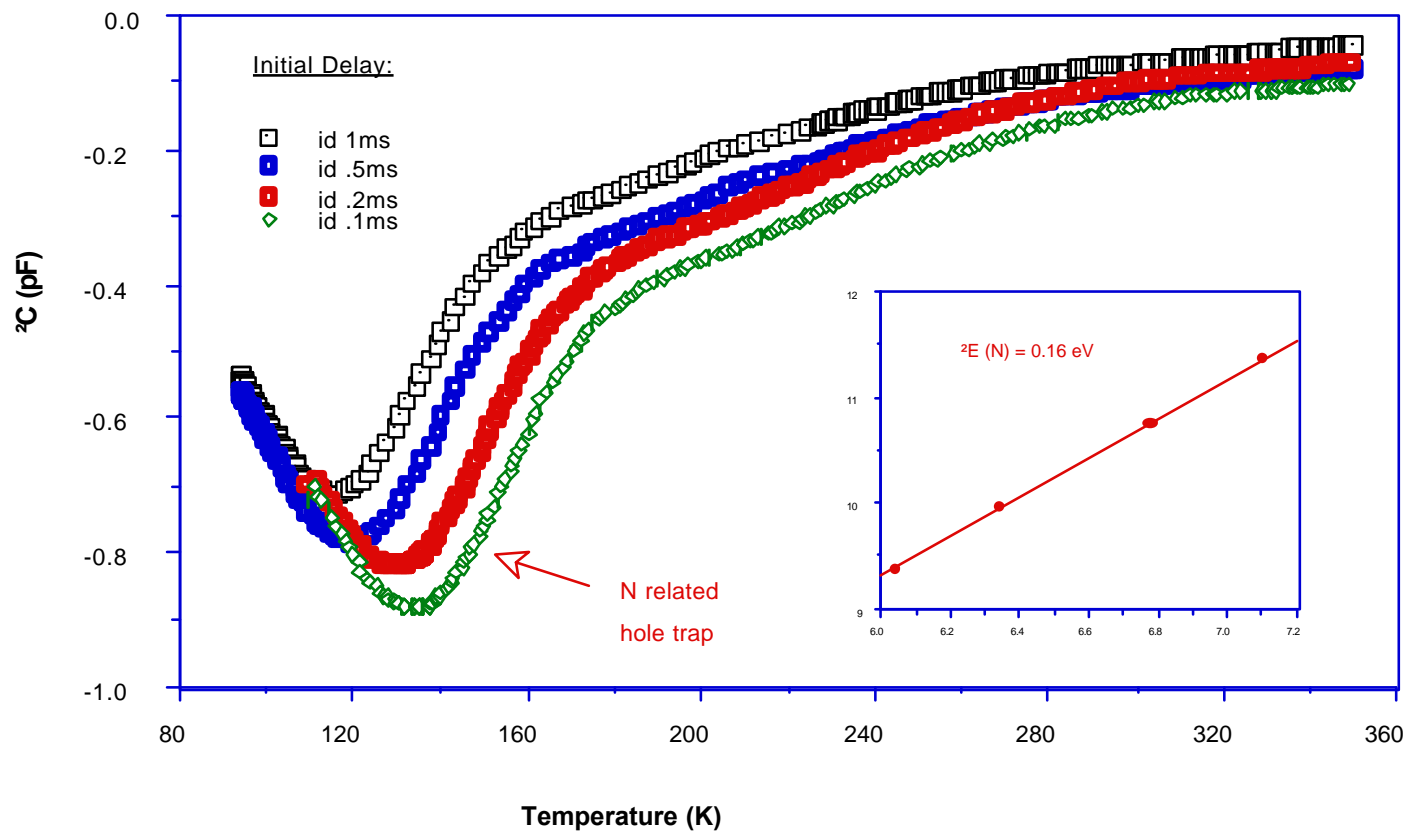

Fig. 6 DLTS spectra and Arrhenius plot of GaInNAs p-n homojunction device.

resulting from structural defects was not observed in any of the GaInNAs devices. A summary of all deep levels detected in samples of different composition are shown in Table, I together with the assignment of their origin.

Table I. Summary of DLTS Levels in GaInNAs films as a Function of Composition

\begin{tabular}{|c|c|c|c|c|c|}
\hline \multirow{2}{*}{$\begin{array}{l}\text { Energy Level } \\
\text { Composition } \\
\end{array}$} & \multicolumn{2}{|c|}{ Nitrogen-Related Levels } & \multicolumn{2}{|c|}{$\begin{array}{l}\text { In-Related } \\
\text { Levels }\end{array}$} & \multirow[t]{2}{*}{ Additional Levels } \\
\hline & $\begin{array}{c}\mathrm{NH} 1 \\
(0.13 \mathrm{eV}) \\
\end{array}$ & $\begin{array}{l}\mathrm{HN} 2 \\
(\mathrm{eV})\end{array}$ & $\begin{array}{c}\mathrm{HIn} \\
(0.36 \mathrm{eV})\end{array}$ & $\begin{array}{l}\text { IIn } \\
(\mathrm{eV})\end{array}$ & \\
\hline $\mathrm{GaN}_{2 \sigma_{6} \mathrm{As}}$ & & 0.22 & & & Hole trap at $0.47 \mathrm{eV}(*)$ \\
\hline $\mathrm{GaN}_{2 \sigma_{6}} \mathrm{As}$ & $\mathrm{x}$ & 0.18 & & & - \\
\hline $\mathrm{GaN}_{3} \%_{6} \mathrm{As}$ & & 0.17 & & & - \\
\hline $\mathrm{GaII}_{3 \%} \mathrm{As}$ & & & & & $0.47(*), 0.53\left(^{*}\right), 0.62(+)$ \\
\hline $\mathrm{GaIn}_{3 \%} \mathrm{As}$ & & & $\mathrm{x}$ & 0.94 & - \\
\hline $\mathrm{GaIn}_{8 \%}$ & & & $\mathrm{x}$ & 0.91 & $0.47(*)$ \\
\hline $\operatorname{GaIn}_{11 \%_{c} \mathrm{~N}_{2.9 \sigma_{c} \mathrm{As}} \mathrm{As}}$ & & 0.21 & $\mathrm{x}$ & & - \\
\hline $\mathrm{GaII}_{8 \%} \mathrm{~N}_{1.2 \%} \mathrm{~N}_{1} \mathrm{As}$ & & 0.18 & $x$ & & - \\
\hline GaAs & & & & & \\
\hline
\end{tabular}

(*) Structural defect

(+) Hole trap due to Fe impurity 


\section{CONCLUSION}

In summary, we have investigated the effect of $\mathrm{N}$ and In doping on the electrical properties of the GaNInAs devices resulting from structural defects and interface states. Moreover, the location and densities of deep levels related to the presence of $\mathrm{N}$, In, and $\mathrm{N}+\mathrm{In}$ are identified and correlated with the device performance. From the above data, it is clear that the presence of $\mathrm{N}$ alone creates a high density of shallow hole traps related to the $\mathrm{N}$ atom and structural defects in the device. Doping by In, if present alone, also creates low-density deep traps (related to the In atom and structural defects) and extremely deep interface states. On the other hand, the co-presence of In and $\mathrm{N}$ eliminates both the interface states and levels related to structural defects (due to reduced lattice-mismatch of GaNInAs with GaAs). However, the device still has a high density of the NH2 shallow traps and the HI deep traps, which are primary contributors

to the photocurrent loss in the GaNInAs device, together with the possible short diffusion length (2).

\section{ACKNOWLEDGMENTS}

This work was supported under Contract No. DE-AC36-83CH10093 with the USDepartment of Energy.

\section{REFERENCES}

(1) Geisz, J. F. et al. Submitted to ICMOVPE-IX Conference Proceedings in J. Cryst. Growth

(2) Friedman, D. et al. (in press) Proceedings of $2^{\text {nd }}$ World Conference on Photovoltaic energy Conversion (1998)

(3) Lang, D. V. J. Appl. Phys. 453023 (1974)

(4) Mitonneau, A., Martin, G. M. and Mircea, A. electron Lett. 13666 (1970).

(5) Du, ,A. Y., Li, M. F. , Chong, T. C., Teo, K. L. , Lau, W. S. , Zhang, Z. , Appl. Phys. Lett. 69 (19) 28491996. 